\title{
Synergistic inhibition of leukemia WEHI-3 cell growth by arsenic trioxide and Hedyotis diffusa Willd extract in vitro and in vivo
}

\author{
YU-JUI KUO ${ }^{1,2}$, YAN-JIN LIU ${ }^{3}$, TZONG-DER WAY ${ }^{4}$, SU-YIN CHIANG $^{5}$, \\ JAUNG-GENG LIN ${ }^{1 *}$ and JING-GUNG CHUNG ${ }^{4,6^{*}}$
}

\author{
${ }^{1}$ Graduate Institute of Chinese Medicine, China Medical University, Taichung 40402; ${ }^{2}$ Department of Traditional \\ Chinese Medicine, Tainan Municipal Hospital, Tainan 70173; ${ }^{3}$ Graduate Institute of Pharmaceutical Chemistry, \\ College of Pharmacy, China Medical University, Taichung 40402; ${ }^{4}$ Department of Biological Sciences and \\ Technology, College of Biopharmaceutical and Food Sciences, China Medical University, Taichung 40402; \\ ${ }^{5}$ Department of Health and Nutrition Biotechnology, College of Health Science, Asia University, Taichung 41354; \\ ${ }^{6}$ Department of Biotechnology, Asia University, Taichung 41354, Taiwan, R.O.C.
}

Received October 22, 2015; Accepted January 13, 2017

DOI: $10.3892 /$ etm.2017.4392

\begin{abstract}
Arsenic trioxide (ATO) is clinically used to treat acute promyelocytic leukemia (APL); however, the therapeutic dose of ATO may prompt critical cardiac side effects. Combination therapy may be used to improve the therapeutic efficiency. To evaluate this possibility, the present study determined the combined effects of Hedyotis diffusa Willd (HDW) extract and ATO in leukemic WEHI-3 cells. The results demonstrated that co-treatment of HDW with ATO resulted in a synergistic augmentation of cytotoxicity in cells at the concentration tested. In order to investigate the potential therapeutic application for leukemia, the combined effects of HDW and ATO were analyzed on the WEHI-3 cell-induced orthotopic leukemia animal model in vivo. The WEHI-3 cells in mice with leukemia were established by injecting murine WEHI-3 cells into BALB/c mice, and treating them with HDW and/or combined with ATO. The results indicated
\end{abstract}

Correspondence to: Professor Jing-Gung Chung, Department of Biological Sciences and Technology, College of Biopharmaceutical and Food Sciences, China Medical University, 91 Hsueh-Shih Road, Taichung 40402, Taiwan, R.O.C.

E-mail: jgchung@mail.cmu.edu.tw

Professor Jaung-Geng Lin, Graduate Institute of Chinese Medicine, China Medical University, 91 Hsueh-Shih Road, Taichung 40402, Taiwan, R.O.C.

E-mail: jglin@mail.cmu.edu.tw

*Contributed equally

Abbreviations: ATO, arsenic trioxide; APL, acute promyelocytic leukemia; TCM, traditional Chinese medicine; FBS, fatal bovine serum; HRP, horseradish peroxidase

Key words: arsenic trioxide, acute promyelocytic leukemia, Hedyotis diffusa Willd, apoptosis, death receptor that HDW alone or HDW combined with ATO promoted the total survival rate of mice with leukemia, and these effects are dose-dependent. HDW alone or HDW combined with ATO did not affect the body weight, decreased the spleen weight and did not affect the liver weight. Furthermore, the results demonstrated that HDW alone or HDW combined with ATO resulted in a synergistic augmentation of apoptosis in WEHI-3 cells at the concentration tested. In order to further reveal the detailed mechanism of this synergistic effect on apoptosis, apoptosis-related proteins were also evaluated. The data revealed that HDW alone or HDW combined with ATO induced the expression of death receptor 4 (DR4) and DR5 and the activation of poly adenosine diphosphate ribose polymerase, caspase-3, -8 and -9 . Furthermore, HDW alone or HDW combined with ATO decreased the expression levels of B-cell lymphoma 2, B-cell lymphoma-extra large and survivin, and increased the expression levels of Bak and t-Bid. Altogether, the results indicate that the combination of HDW with ATO may be a promising strategy used to increase the clinical efficacy of ATO in the treatment of APL.

\section{Introduction}

Leukemia, one of the major causes of death for patients with cancer, is a group of cancers that typically begins in the bone marrow and results in high numbers of abnormal white blood cells. Arsenic trioxide (ATO), an agent currently used in clinical practice, has been adopted from traditional Chinese medicine (TCM). ATO is used as a first-line drug for acute promyelocytic leukemia (APL) due to its apoptosis-inducing properties in leukemia cells. However, the treatment of leukemia with ATO remains unsatisfactory (1). Its therapeutic potential and anti-cancer activity have been investigated in various types of solid tumors, including esophageal, prostate and ovarian carcinomas (2-4). Increasing evidence has also demonstrated that ATO may be applied for the treatment of various solid tumors due to its ability to trigger apoptotic cell death (5). 
Numerous previous clinical reports have reported that chronic exposure to a therapeutic dose of ATO may evoke severe cardiac side effects and result in sudden cardiac death in certain cases (6-9) and long-term exposure to ATO results in an increased likelihood of cardiovascular disease in patients with APL. Therefore, prophylactic measures used to manage the consequent cardiotoxicity in clinical applications of ATO are urgently required (10). Combination therapy is a frequently used strategy in clinics to improve, therapeutic efficiency; therefore, identifying agents to enhance the efficacy of ATO against human tumors and to reduce the severe cardiac side effects is necessary.

Hedyotis diffusa Willd (HDW), an annual herb that belongs to the Rubiaceae family, has been used in TCM for thousands of years (11). HDW is used as a cancer therapy agent, which reduces the adverse reactions of chemotherapy (12). Several reports have demonstrated that the extract of HDW exerts its therapeutic effects by inducing mitochondrial apoptosis in numerous human cancer cell lines (13-15). Through targeting multiple signaling pathways, HDW has been revealed to induce cell-cycle arrest and suppress inflammation molecules $(15,16)$. The major components of HDW include ursolic and oleanolic acid, polysaccharide, favone, amongst others, which lead to the herb's anti-tumor properties.

Our previous study demonstrated that HDW promoted the immune response and exhibited anti-leukemic activity in BALB/c leukemic mice in vivo (11). HDW is widely used in combination with other herbal medicines to treat various types of cancer (17). Furthermore, recurrent cancer patients typically use HDW during chemotherapy to achieve additive or synergistic therapeutic effects (18-20). Therefore, the aim of the present study was to evaluate the efficacy of combining HDW with ATO as a novel strategy for promoting the clinical efficacy of ATO in APL. The present results demonstrated that a combination of HDW and ATO synergistically increased the cytotoxicity and apoptotic cell death in WEHI-3 cells in vitro and in vivo. In addition, the molecular mechanism of this synergistic effect of HDW and ATO was investigated further. The observations of the present study provide preclinical evidence for the potential efficacy of using the two agents in combination therapy to treat APL.

\section{Materials and methods}

Materials. Prestoblue Cell Viability reagent, RPMI-1,640 and fetal bovine serum (FBS) were purchased from Invitrogen (Thermo Fisher Scientific, Inc., Waltham, MA, USA) and methanol was purchased from Avantor Performance Materials (Center Valley, PA, USA). Primary antibodies against caspase-3 (no. 9662), caspase-8 (no. 4927) and caspase-9 (no. 9508), poly adenosine diphosphate ribose polymerase (PARP; no. 9532), B-cell lymphoma-extra large (Bcl-xL; no. 2764), survivin (no. 2808), Bak (no. 12105), Bid (no. 2003), death receptor 4 (DR4; no. 42533) and $\beta$-actin (no. 3700) were purchased from Cell Signaling Technology, Inc. (Danvers, MA, USA). Antibodies against B-cell lymphoma 2 (Bcl-2; sc-509) were purchased from Santa Cruz Biotechnology, Inc. (Dallas, TX, USA). Antibodies against death receptor 5 (DR5; ab8416) were purchased from Abcam (Cambridge, MA, USA). Horseradish peroxidase (HRP)-conjugated goat anti-mouse immunoglobulin (Ig)G (AP124P) and goat anti-rabbit IgG (AP132P) secondary antibodies were obtained from EMD Millipore (Billerica, MA, USA).

Preparation of HDW. HDW plants were dried and ground into a fine powder. HDW $(500 \mathrm{~g})$ was extracted with $5,000 \mathrm{ml}$ of $50 \%$ ethanol using the refluxing method, and was then filtered. The ethanol solvent was then evaporated on a rotary evaporator in a water bath at $60^{\circ} \mathrm{C}$ for $24 \mathrm{~h}$. In addition, the dried powder of HDW was obtained via a spraying desiccation method using a spray dryer. Stock solutions of HDW were prepared by dissolving the powder in dimethyl sulfoxide (DMSO) to a concentration of $100 \mathrm{mg} / \mathrm{ml}$ and stored at $-20^{\circ} \mathrm{C}$. The working concentrations of HDW were subsequently prepared by diluting the stock solution in RPMI-1640 medium, and the final concentration of DMSO in the medium was stored at $<0.2 \%$.

Cell lines and cell culture. The WEHI-3 murine myelomonocytic leukemia cell line was obtained from the Food Industry Research and Development Institute (Hsinchu, Taiwan). Cells were cultured in RPMI-1640 medium containing 10\% FBS, penicillin $(100 \mathrm{IU} / \mathrm{ml})$ and streptomycin $(100 \mu \mathrm{g} / \mathrm{ml})$ at $37^{\circ} \mathrm{C}$ under a humidified $5 \% \mathrm{CO}_{2}$ atmosphere until use in further experiments. The morphology of cells was observed by a photomicroscope (21).

Cell viability assay. The cell viability assay was performed using Prestoblue Cell Viability reagent (Invitrogen; Thermo Fisher Scientific, Inc.). WEHI-3 cells ( $2 \times 10^{4}$ cells/well) were seeded in 96-well plates. The cells were incubated with increasing concentrations $(0.1,0.2,0.4,0.8,1.6 \mathrm{mg} / \mathrm{ml})$ of HDW and ATO $(0.8,1.6,3.2,6.4$ and $12.8 \mu \mathrm{M})$ for 24 and $48 \mathrm{~h}$ at $37^{\circ} \mathrm{C}$. Following incubation, $10 \mu \mathrm{l}$ Prestoblue Cell Viability reagent was added to each well and incubated for $3 \mathrm{~h}$ at $37^{\circ} \mathrm{C}$, following which the media was discarded. Violet formazan precipitate was dissolved in $100 \mu \mathrm{l}$ of DMSO and the color absorbance was recorded at $570 \mathrm{~nm}$ using a microplate reader. The control value corresponding to untreated cells was taken as $100 \%$ and the viability of treated samples were expressed as a percentage of the control.

Establishment of leukemic mice and treatment with indicated agents. Male BALB/c mice, 22-28 g in weight and 4-6 weeks of age, were obtained from the National Laboratory Animal Center (Taipei, Taiwan). A total of 54 mice were randomly divided into 9 groups ( $\mathrm{n}=6$ each) and subsequently received different treatments as described below. WEHI-3 cells ( $1 \times 10^{5}$ cells $/ 0.1 \mathrm{ml} /$ mouse) were intraperitoneally (i.p.) administered to mice and two weeks later, the mice were successfully induced as a model of leukemia. Group I mice served as untreated controls; group II mice were i.p. injected with WEHI-3 cells to form the leukemia group; group III mice were treated with crude extracts of HDW $(100 \mathrm{mg} / \mathrm{kg})$ in double distilled water (DDW) following i.p. injection of WEHI-3 cells; group IV mice were treated with crude extracts of HDW (250 $\mathrm{mg} / \mathrm{kg}$ ) in DDW following i.p. injection of WEHI-3 cells; group V mice were treated with crude extracts of HDW $(500 \mathrm{mg} / \mathrm{kg})$ in DDW following i.p. injection of WEHI-3 cells; group VI mice were treated with ATO $(5 \mathrm{mg} / \mathrm{kg})$ following 
i.p. injection of WEHI-3 cells; group VII mice were treated with ATO $(5 \mathrm{mg} / \mathrm{kg})$ and HDW $(100 \mathrm{mg} / \mathrm{kg})$ following i.p. injection of WEHI-3 cells; group VIII mice were treated with ATO $(5 \mathrm{mg} / \mathrm{kg})$ and HDW $(250 \mathrm{mg} / \mathrm{kg})$ following i.p. injection of WEHI-3 cells and group IX mice were treated with ATO $(5 \mathrm{mg} / \mathrm{kg})$ and HDW $(500 \mathrm{mg} / \mathrm{kg})$ following i.p. injection of WEHI-3 cells. The crude extract of HDW was administered via oral gavage to each mouse from the treatment groups with the above doses on a daily basis for 2 weeks, and each mouse was subsequently weighed. Mice were maintained at a constant temperature of $25 \pm 1^{\circ} \mathrm{C}$ in $55 \%$ humidity with a $12 \mathrm{~h}$ light/dark cycle, and were regularly provided with food and water. Ethical approval was granted by the Institutional Animal Care and Use Committee (no. 2016-091). The mice were sacrificed with $\mathrm{CO}_{2}$ for further studies.

Spleen and liver tissues collections. Spleen and liver samples were isolated from all mice and weighed individually, following sacrifice as previously described (22).

Western blot analysis. WEHI-3 cells were plated in a $10 \mathrm{~cm}$ dish and exposed to the indicated concentrations of HDW and ATO for $48 \mathrm{~h}$. Cells were harvested and lysed in ice-cold radioimmunoprecipitation assay buffer $(50 \mathrm{mM}$ Tris, pH 7.4, $150 \mathrm{mM} \mathrm{NaCl}, 1 \mathrm{mM}$ EDTA, $1 \%$ Triton X-100, $1 \%$ deoxycholate, $0.1 \%$ SDS, $1 \mathrm{mM}$ dithiothreitol and $10 \mu 1 / \mathrm{ml}$ protease inhibitor cocktail; Sigma-Aldrich, Merck KGaA, Darmstadt, Germany). Whole cell lysates $(50 \mu \mathrm{g})$ with equal protein concentrations were obtained using the Protein Assay kit from Bio-Rad Laboratories, Inc. (Hercules, CA, USA) according to the manufacturer's protocol and further separated by SDS-PAGE (8-12\%) and transferred onto a polyvinylidene fluoride membrane (EMD Millipore) as previously described (23-25). After blocking the membrane with blocking buffer [Tris-buffered saline with Tween-20 (TBST) containing $5 \%$ non-fat milk and $\left.0.1 \% \mathrm{NaN}_{3}\right]$, they were hybridized separately with primary antibodies. All primary antibodies were diluted with antibody buffer (TBST containing 5\% bovine serum albumin and $0.1 \% \mathrm{NaN}_{3}$ ) to a dilution of 1:1,000. Finally, the membrane was hybridized with secondary antibody (HRP-conjugated goat anti-mouse $\mathrm{IgG}$ or goat-rabbit IgG at a dilution of 1:5,000), and protein bands were presented using enhanced chemiluminescence western blot analysis detection reagents (GE Healthcare Life Sciences, Chalfont, UK). The density of each band was quantified by ImageJ version 1.47 (National Institutes of Health, Bethesda, MA, USA).

Statistical analysis. Each experiment was repeated at least three times and data are presented as the mean \pm standard deviation $(\mathrm{n}=6)$. All data were analyzed using IBM SPSS software (version 22.0 for Windows; IBM SPSS, Armonk, NY, USA). Differences between the control and experimental groups were analyzed using independent Student's t-test when $\mathrm{P}<0.05$ was considered to indicate a statistically significant difference.

\section{Results}

Synergistic effects of HDW and ATO on cell viability in WEHI- 3 cells. The combined effect of HDW and ATO exposure compared with individual exposure to both agents were initially observed at 24 and $48 \mathrm{~h}$ to elucidate whether combination therapy may result in a longer-lived restriction of cell proliferation compared with individual therapies. As shown in Fig. 1, following treatment with an indicated concentration of ATO or HDW, the cell viability of WEHI-3 cells was markedly decreased in a dose- and time-dependent manner. Notably, the combination of ATO and HDW synergistically reduced the viability of WEHI-3 cells, demonstrating a lower cell survival rate compared with those of single ATO- or HDW-treated groups. These results indicate that a combination of ATO with HDW is capable of increasing the sensitivity of ATO for killing leukemia cells.

Synergistic effects of $H D W$ and $A T O$ on $B A L B / c$ mice following i.p. injection with WEHI-3 cells. The combined effect of HDW and ATO on BALB/c mice was examined following i.p. injection with WEHI-3 cells. The procedure of leukemic mice establishment and treatment are presented in Fig. 2A. All mice were weighed and the mean weight of each group is presented in Fig. 2B, which indicates that oral treatment of HDW and ATO alone or a combination of HDW and ATO did not significantly affect the body weight of mice with leukemia. Furthermore, the survival rate of tumor-bearing mice was markedly reduced in the $500 \mathrm{mg} / \mathrm{kg} / \mathrm{day}$ HDW group and $5 \mathrm{mg} / \mathrm{kg}$ /day ATO group (Fig. 2C), respectively. Based on these observations, HDW and ATO alone may have effective anti-leukemic activity in WEHI-3 cells in vivo.

Combination of HDW and ATO affects spleen and liver weights of leukemic BALB/c mice. Mice were sacrificed following treatment with the indicated agents, and the spleen and liver was harvested from each mouse. Representative spleens are presented in Fig. 3A, which indicate that HDW and ATO treatments alone were able to reduce the size of the spleen, and that increasing the dose of HDW led to a greater reduction in the spleen size. The combination of $5 \mathrm{mg} / \mathrm{kg} / \mathrm{day}$ ATO with 250 or $500 \mathrm{mg} / \mathrm{kg} / \mathrm{day}$ HDW was also shown to be capable of reducing the size of the spleen $(\mathrm{P}<0.05$ and $\mathrm{P}<0.01$, respectively; Fig. 3B). Liver tissues were weighed, and the results are presented in Fig. 3C. The combination of $250 \mathrm{mg} / \mathrm{kg} / \mathrm{day}$ HDW and $5 \mathrm{mg} / \mathrm{kg} / \mathrm{day}$ ATO and $500 \mathrm{mg} / \mathrm{kg} / \mathrm{day}$ HDW and $5 \mathrm{mg} / \mathrm{kg} /$ day ATO significantly reduced the weights of spleen when compared with the leukemia control group $(\mathrm{P}<0.05$ and $\mathrm{P}<0.01$, respectively; Fig. 3B). However, oral treatment of HDW or ATO alone, or combination of HDW and ATO did not significantly affect the weights of liver samples (Fig. 3C).

HDW induces apoptosis via activation of the DR4 and DR5 signaling pathway in WEHI-3 cells. Our recent study demonstrated that HDW-induced apoptosis in HL-60 cells may be due to the induction of the DR pathways (26). The present study evaluated whether HDW was able to induce apoptosis through the induction of the DR pathways in WEHI-3 cells. HDW treatment induced an increase in DR4 and DR5 expression (Fig. 4A) in a dose-dependent manner; indicating that DR4 and DR5 upregulation are important in HDW-mediated apoptosis in leukemia cells.

Synergistic effects of HDW and ATO on the activation of the DR4 and DR5 signaling pathway in WEHI-3 cells. The 
A

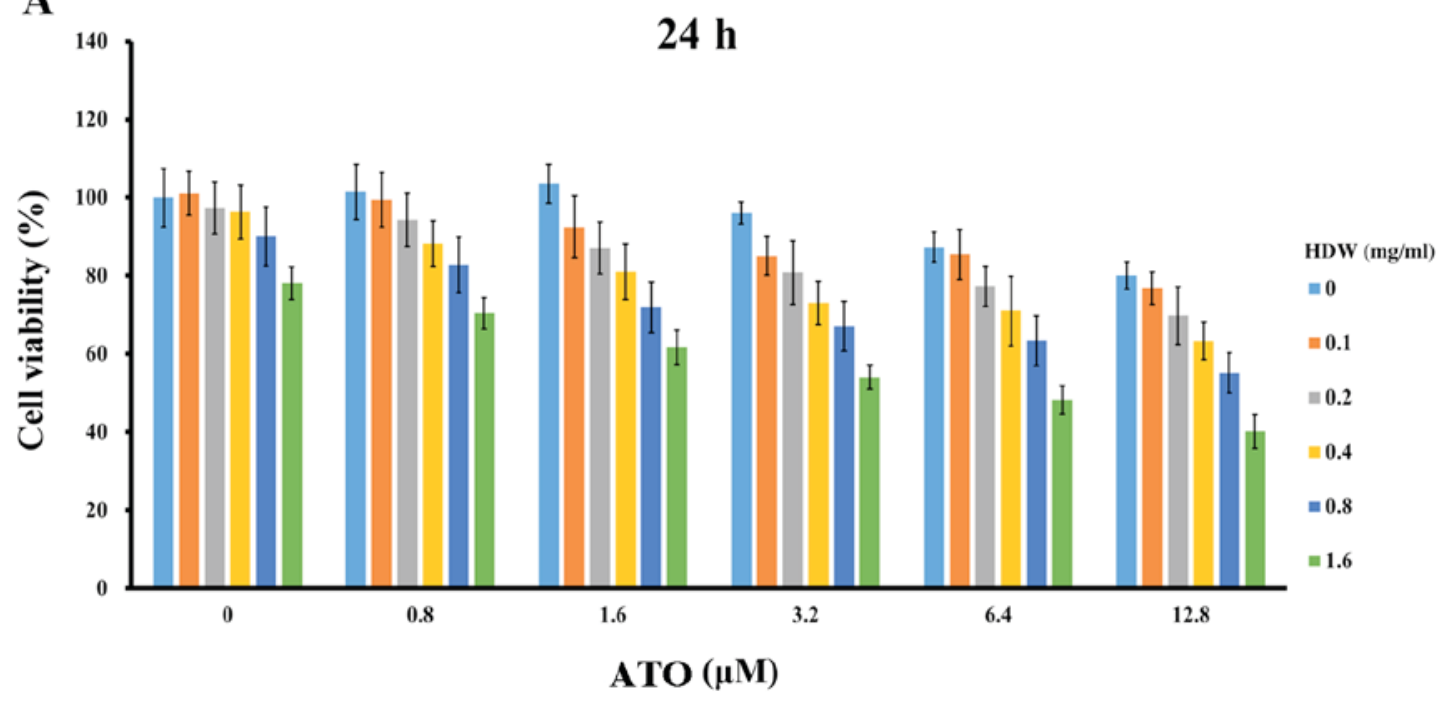

B

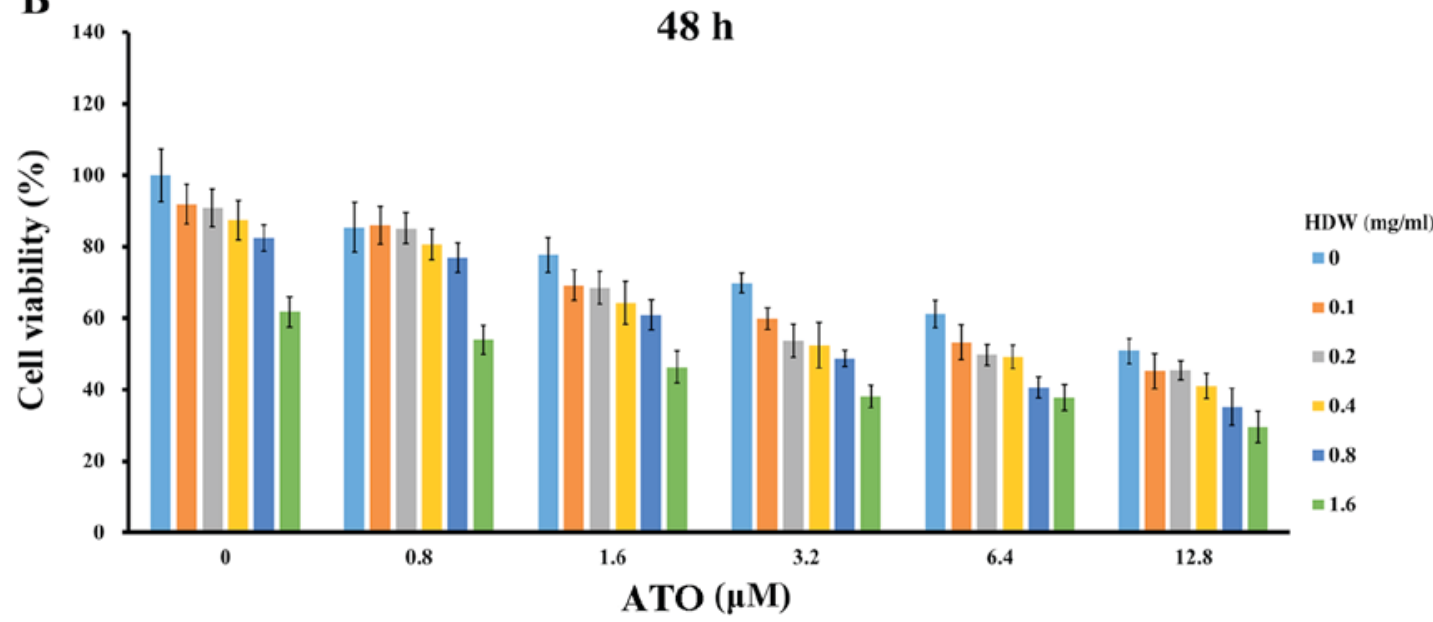

Figure 1. Effect of the combination of HDW and ATO on anti-proliferation activity. WEHI-3 cells were treated with the indicated concentration of ATO or HDW, or ATO and HDW for (A) 24 and (B) 48 h, and viability was measured by the Prestoblue Cell Viability reagent assay. This experiment was repeated three times. The data represented are the mean \pm standard deviation. HDW, Hedyotis diffusa Willd; ATO, arsenic trioxide.

synergistic effects of HDW and ATO on the activation of DR4 and DR5 was examined. As shown in Fig. 4B, the expression levels of DR4 and DR5 were markedly increased following treatment with HDW or ATO alone, compared with control cells. Furthermore, the combination treatment of HDW and ATO induced a higher expression of DR4 and DR5 compared with those in the single HDW or ATO-treated group. The results revealed that the synergistic effects of HDW and ATO on cell viability are via the activation of the DR4 and DR5 signaling pathway in WEHI-3 cells.

HDW-stimulated apoptosis occurs through the induction of PARP, caspase-3, -8 and -9 activities. Caspase activation is crucial in the initiation and execution of apoptosis. In order to determine whether HDW-stimulated apoptosis went through the activation of caspase, WEHI-3 cells were treated with or without the indicated concentration of HDW for $48 \mathrm{~h}$ prior to assessment of PARP, caspase- $3,-8$ and -9 protein levels. Fig. 5A demonstrates that HDW upregulated the levels of cleaved PARP, cleaved caspase- 8 and cleaved caspase- 9 expression, whereas levels of pro-caspase-3 were downregulated in
WEHI-3 cells. These results suggest that the caspase cascade contributed to HDW-induced apoptosis in WEHI-3 cells.

Effects of HDW on levels of Bcl-2 family proteins. The association between HDW and the levels of Bcl-2 family proteins was subsequently examined. Fig. 5B demonstrates that HDW administration decreased anti-apoptotic protein levels in a dose-dependent manner. Furthermore, treatment with HDW decreased the total Bcl-2, Bcl-xL and survivin protein levels, respectively. In addition, our data revealed that HDW increased the expression of Bak in a dose-dependent manner, and that Bid, a substrate of caspase-8, was also activated by HDW (Fig. 5C).

Synergistic effects of HDW and ATO on the expression of apoptosis-related proteins in WEHI-3 cells. As shown in Fig. 6A, following treatment with HDW or ATO alone, the activation of PARP and caspase-3, -8 and -9 was increased compared with the control cells. The combination treatment of HDW and ATO induced a higher activation of PARP, caspase- $3,-8$ and -9 than those in the single HDW or ATO-treated groups (Fig. 6A). As depicted in Fig. 6B and C, the 
A

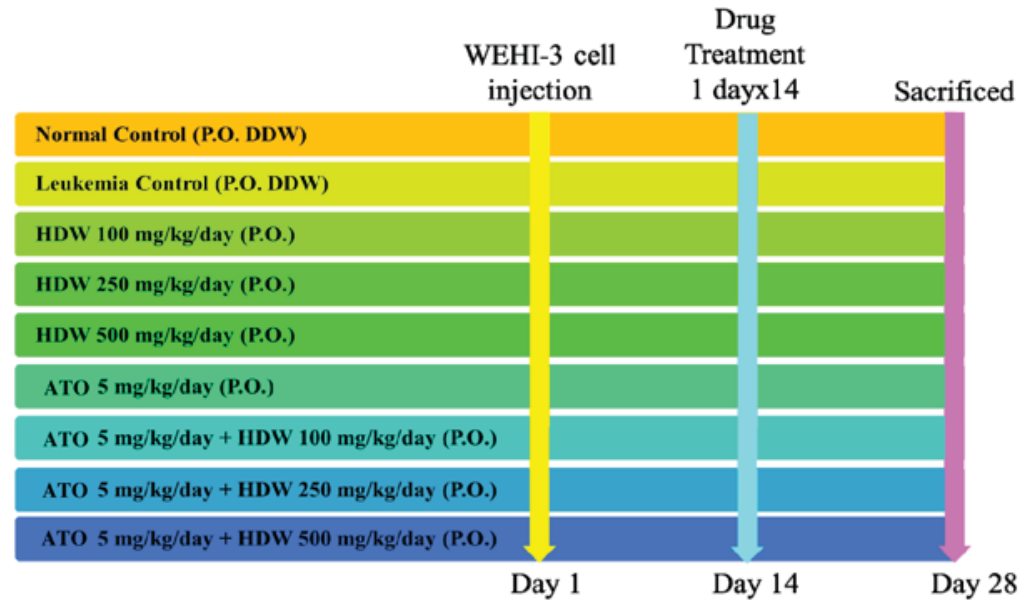

B
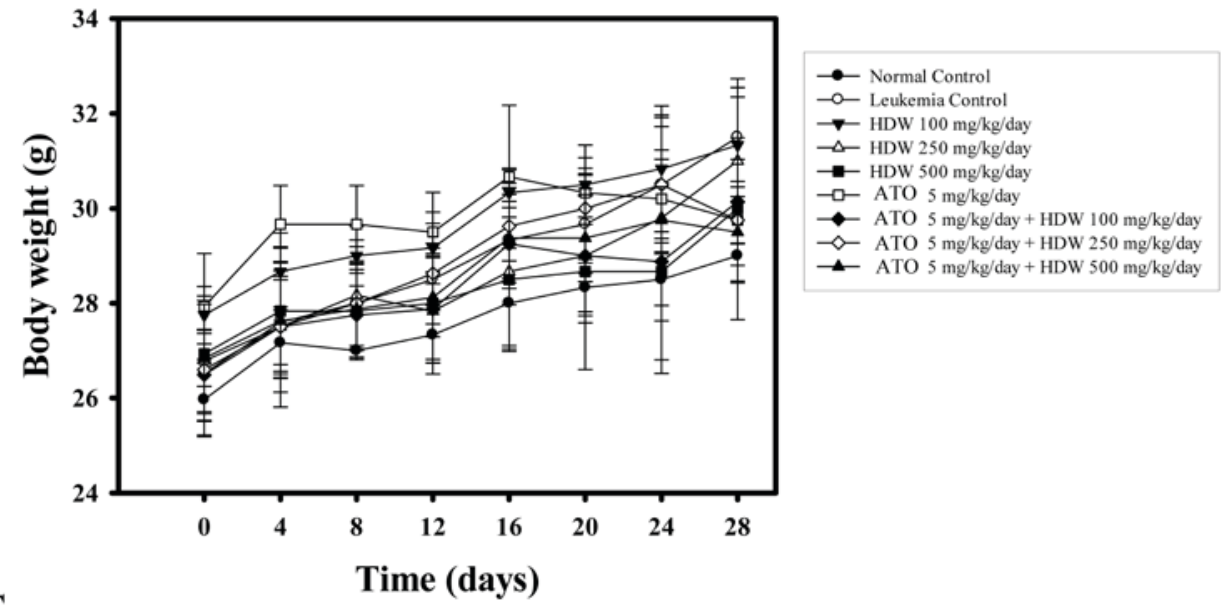

C

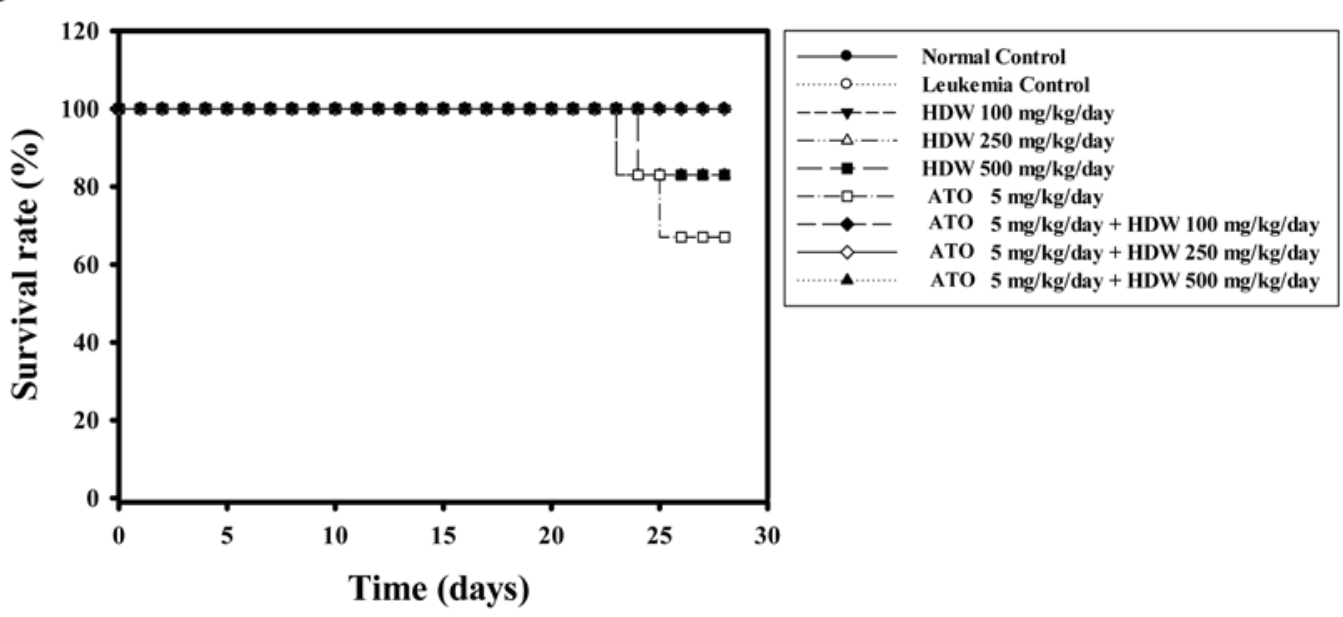

Figure 2. Effect of the combination of HDW and ATO on BALB/c mice following i.p. injection with WEHI-3 cells. (A) The procedure of leukemic mice establishment and treatment. (B) Mice were i.p. injected with WEHI-3 cells and subsequently orally treated with HDW, ATO or a combination of ATO and HDW for 2 weeks. All individual mice were weighed and the average weight of all mice from each group is shown. (C) The survival rate of tumor-bearing mice. The data represent the mean \pm standard deviation. HDW, Hedyotis diffusa Willd; ATO, arsenic trioxide; i.p, intraperitoneal; P.O., oral gavage; DDW, double-distilled water.

cells exposed to HDW or ATO alone markedly decreased the expression levels of Bcl-2, Bcl-xL and survivin, and increased the expression levels of Bak and t-Bid when compared with control cells. Notably, co-treatment of cells with HDW and ATO enhanced the effect in comparison with cells treated with HDW or ATO alone. These observations collectively suggest that combination treatment of WEHI-3 cells with HDW and
ATO activated the intrinsic mitochondrial and extrinsic DR pathways to induce cell apoptosis.

\section{Discussion}

ATO was initially used as a chemotherapeutic agent in APL, and it has previously been indicated that it may be used to 
A

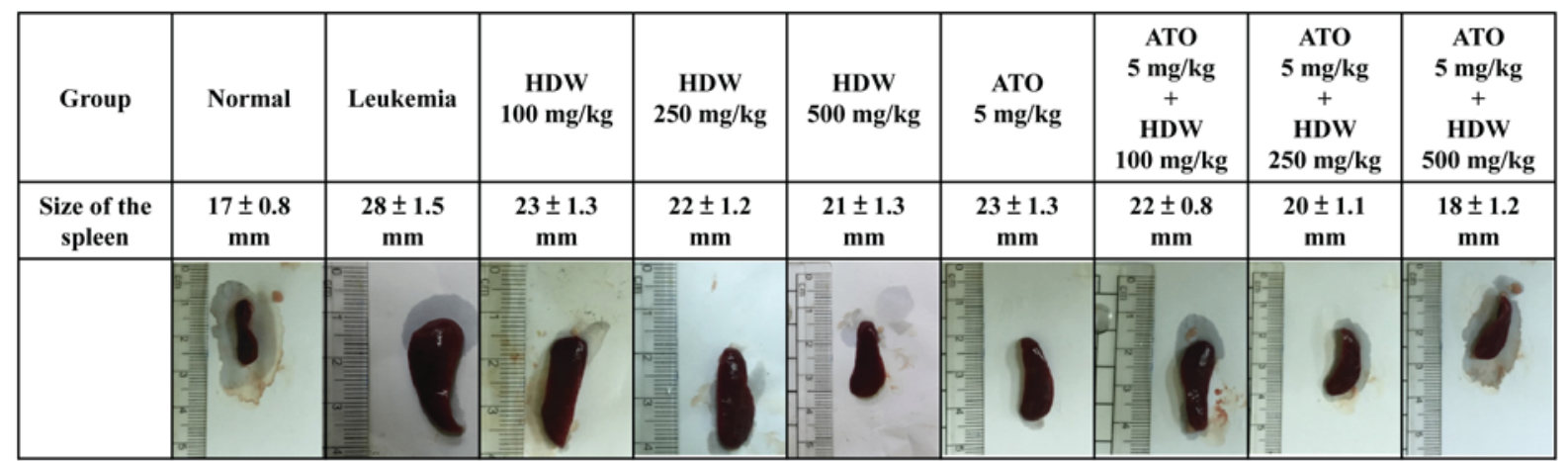

B

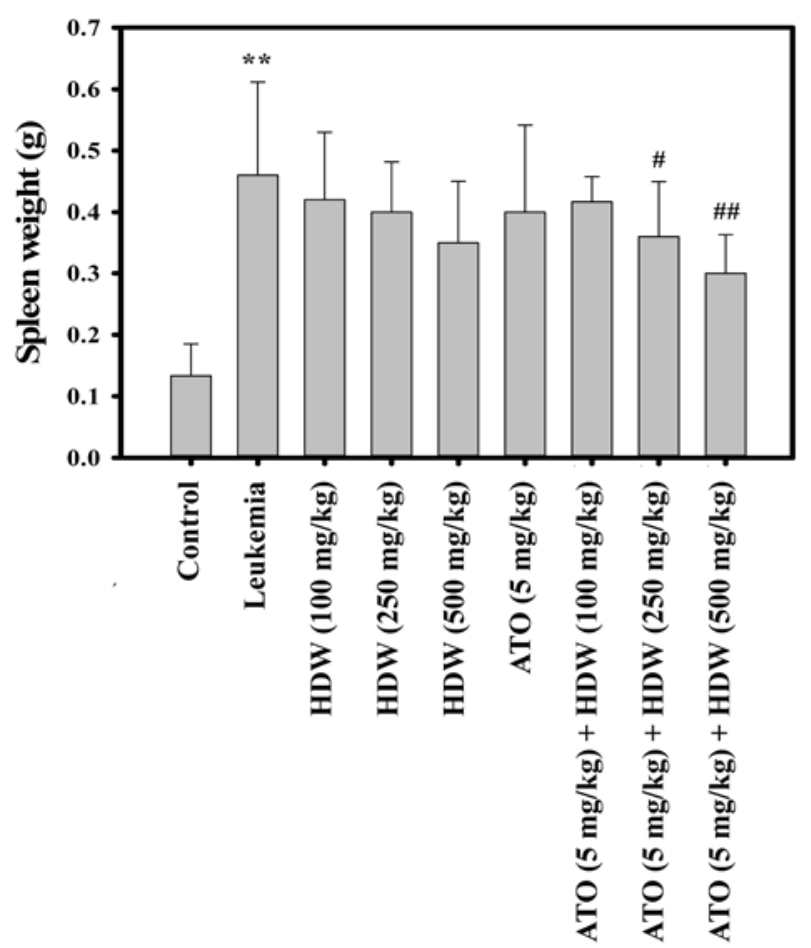

C

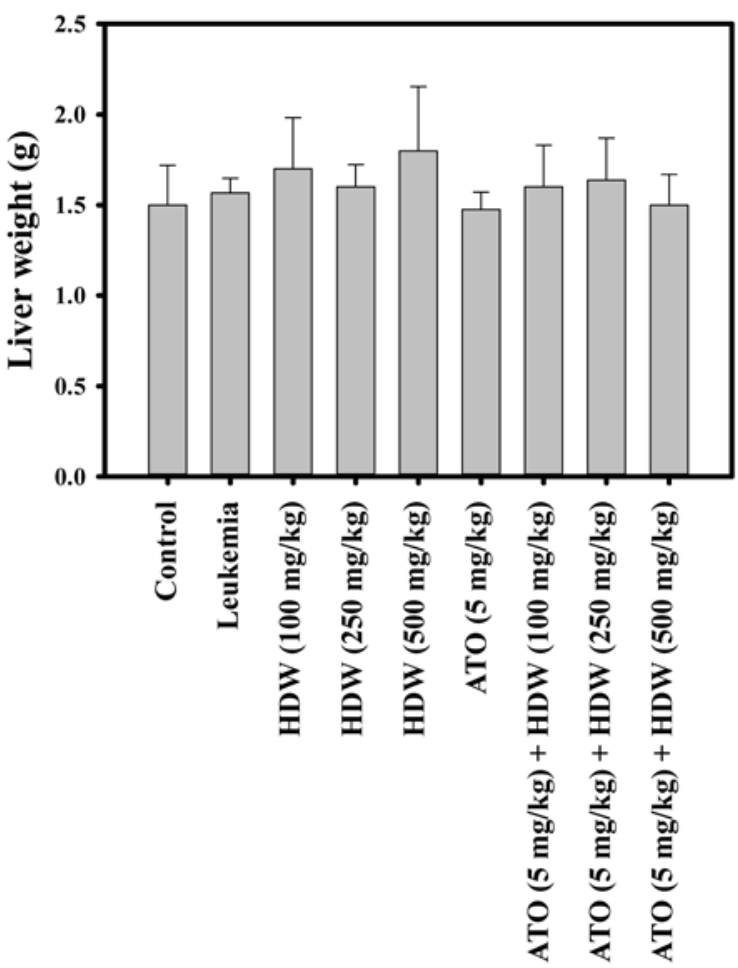

Figure 3. Effect of HDW and/or ATO on spleen or liver tissue weight in leukemic BALB/c mice. (A) Representative spleen tissue in leukemic BALB/c mice following exposure to HDW and/or ATO. BALB/c mice were intraperitoneally administered WEHI-3 leukemia cells and after 2 weeks were orally treated with HDW (100, 250 and $500 \mathrm{mg} / \mathrm{kg} / \mathrm{day})$ and $/$ or ATO $(5 \mathrm{mg} / \mathrm{kg} / \mathrm{day})$ for 2 weeks. Mice were then sacrificed, images were captured and representative spleen tissues are shown. (B) At 4 weeks, the spleen tissue weight was estimated. (Values are the mean \pm standard deviation; $\mathrm{n}=6$ ). ${ }^{* *} \mathrm{P}<0.01$ vs. normal control group; ${ }^{*} \mathrm{P}<0.05$ and ${ }^{\# /} \mathrm{P}<0.01$ vs. leukemia control group. (C) At 4 weeks, the liver tissue weight was estimated. (Values are the mean $\pm \mathrm{SD} ; \mathrm{n}=6$ ). HDW, Hedyotis diffusa Willd; ATO, arsenic trioxide; S.D. standard deviation.

A

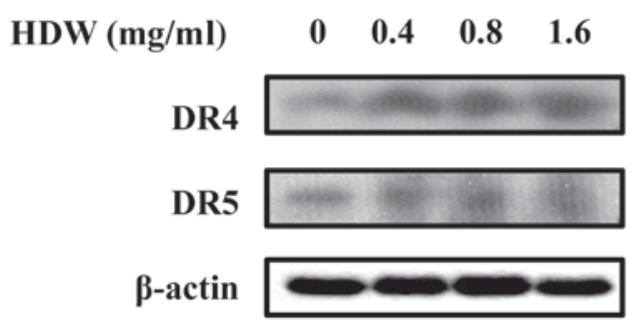

B

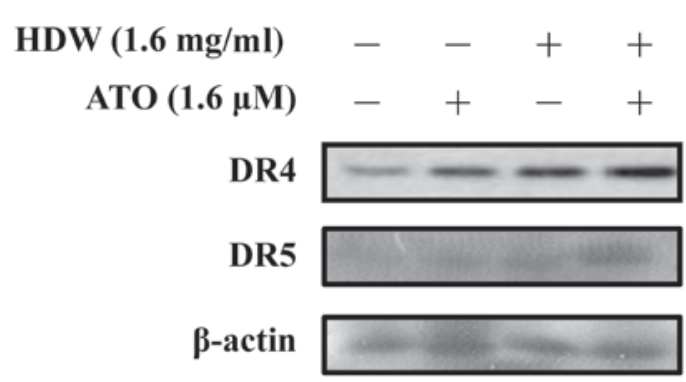

Figure 4. Effect of HDW and/or ATO on the activation of the DR4 and DR5 signaling pathway. (A) WEHI-3 cells treated with HDW at $0.4,0.8$ and $1.6 \mathrm{mg} / \mathrm{ml}$ for $48 \mathrm{~h}$. (B) WEHI-3 cells were treated with $1.6 \mathrm{mg} / \mathrm{ml} \mathrm{HDW}$ and $1.6 \mu \mathrm{M}$ ATO or a combination of HDW and ATO for $48 \mathrm{~h}$. The protein expression of DR4, DR5 and $\beta$-actin was measured by western blotting. Western blotting data presented are representative of those obtained in at least three separate experiments. HDW, Hedyotis diffusa Willd; ATO, arsenic trioxide; DR, death receptor. 
A


B

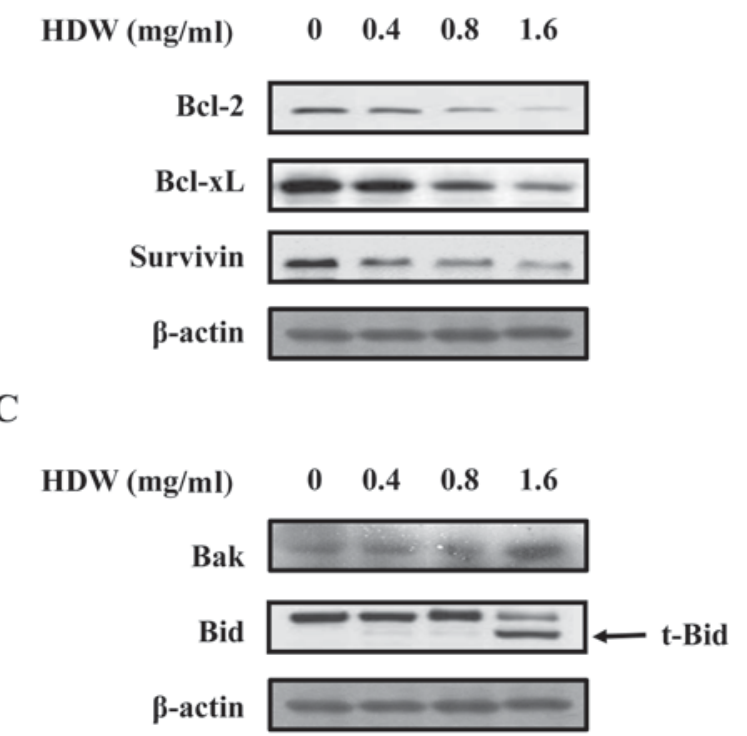

Figure 5. Effect of HDW on apoptosis-related proteins. WEHI-3 cells treated with HDW at $0.4,0.8$ and $1.6 \mathrm{mg} / \mathrm{ml}$ for $48 \mathrm{~h}$. (A) The protein expression of PARP, and caspase- $3,-8$, and -9 was measured by western blotting. (B) The protein expression of $\mathrm{Bcl}-2, \mathrm{Bcl}-\mathrm{xL}$ and survivin was measured by western blotting. (C) The protein expression of Bak and Bid was also measured by western blotting. Western blot data presented are representative of those obtained in at least three separate experiments. HDW, Hedyotis diffusa Willd; PARP, poly adenosine diphosphate ribose polymerase; Bcl, B-cell lymphoma; xL, extra large; t-Bid, truncated Bid.

treat various types of cancers, including solid cancers (2-4). However, the therapeutic dose of ATO may evoke severe cardiac side effects. Therefore, combining therapeutics may be a novel strategy for promoting the clinical efficacy of ATO in APL. In the present study, whether HDW was able to enhance the sensitivity of ATO in the therapy of leukemia was evaluated. It was demonstrated that co-treatment of HDW with ATO synergistically inhibited cell proliferation and induced apoptotic cell death in WEHI-3 cells. To the best of our knowledge the present study identified, for the first time, the synergistic effects of HDW and ATO on BALB/c mice following i.p. injection with WEHI-3 cells.

In our previous study, murine WEHI-3 leukemia was established in BALB/c mice and HDW was hypothesized to have anti-leukemic effects on leukemic animals in vivo. Following i.p. injection with WEHI-3 cells, the major characteristic of leukemic mice were enlarged spleen cells. HDW extract reduced the weights of the spleen and liver, but had no significant effect on the body weight in WEHI-3 leukemic mice (11).
A

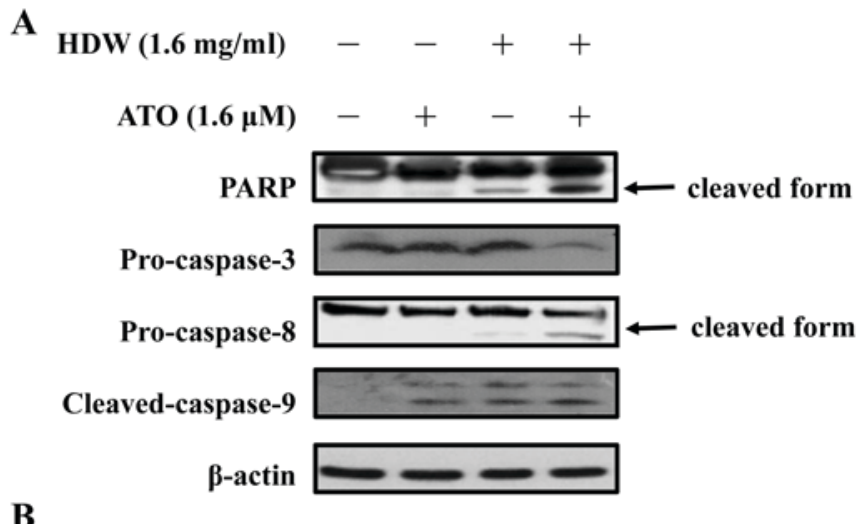

B
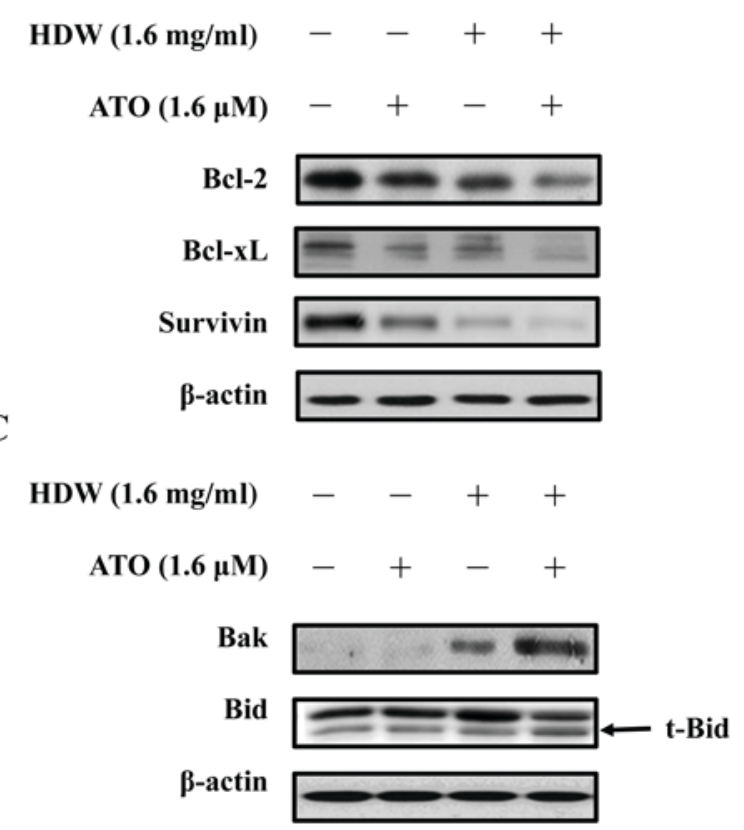

Figure 6. Effect of HDW and/or ATO on apoptosis-related proteins. WEHI-3 cells were treated with $1.6 \mathrm{mg} / \mathrm{ml} \mathrm{HDW}, 1.6 \mu \mathrm{M}$ ATO or a combination of HDW and ATO for $48 \mathrm{~h}$. (A) The protein expression of PARP, and caspase- 3 , -8 , and -9 was measured by western blotting. (B) The protein expression of $\mathrm{Bcl}-2, \mathrm{Bcl}-\mathrm{xL}$ and survivin was also measured by western blotting, as well as the protein expression of (C) Bak and Bid. Western blot data presented are representative of those obtained in at least three separate experiments. HDW, Hedyotis diffusa Willd; ATO, arsenic trioxide; PARP, poly adenosine diphosphate ribose polymerase; Bcl, B-cell lymphoma; xL, extra large.

Furthermore, HDW increased the percentage of CD11b cell surface marker (monocytes) and reduced the percentage of CD3 (T-cell) and CD19 (B-cell) markers. In the present study, oral treatment of HDW or ATO only, or combination of HDW and ATO was demonstrated to prolong the survival of tumor-bearing mice. Results from in vivo experiments indicated that the combination of HDW and ATO significantly reduced the weights of the spleen when compared with the HDW or ATO alone groups.

Given that in vitro evaluation of cytotoxicity in cancer cells is necessary for determining the potential therapeutic efficiency of combination therapy, a Prestoblue Cell Viability reagent assay was performed. The results revealed that WEHI-3 cells treated with HDW and ATO exhibited a higher cytotoxicity than single agent-treated cells (Fig. 1). Both HDW and ATO possess chemotherapeutic potential due to their ability to trigger apoptosis in several cancer types. Furthermore, our 
previous study indicated that HDW induces apoptosis in human leukemia cells by modulating caspase cascade signaling (26). Zhang et al (27) identified that HDW inhibited the growth of human glioblastoma cells by inducing mitochondrial apoptosis via the AKT/ERK pathways. A recent study revealed that HDW directly inhibited the proliferation of cervical cancer cells and induced apoptosis of the tumor cells (28). Moreover, Gao et al (29) indicated that ATO treatment effectively caused cell growth inhibition, suppressed clonogenic potential and induced G2-M cell cycle arrest and apoptosis in pancreatic cancer cells. ATO was also able to induce apoptosis in human hepatocellular carcinoma HepG2 cells through a reactive oxygen species-mediated mitochondrial pathway and activation of caspases (30). Therefore, the present study further evaluated the potential effects of combination HDW and ATO treatment on cell apoptosis. The results demonstrated that the level of apoptosis was elevated by either HDW or ATO alone, and the percentage of apoptosis in the cells co-treated with both agents was higher than that of cells treated with single HDW or ATO. These observations indicate that the synergistic cytotoxic effects of HDW and ATO may come from cell apoptosis. In order to further explore the detailed mechanism of apoptosis induced by HDW and/or ATO, the expression of key molecules of the extrinsic and intrinsic apoptotic pathway was detected by western blot analysis. The results revealed that HDW and ATO were able to induce the activation of DR4 and DR5 in WEHI-3 cells. Notably, WEHI-3 cells co-treated with HDW and ATO demonstrated higher expression of these proteins compared with single agent-treated cells, indicating that HDW and ATO may share the same apoptotic signaling pathways used to initiate apoptosis.

The Bcl-2 family is important in the intrinsic apoptotic pathway, by controlling the release of cytochrome $c$ from mitochondria to the cytosol and then sequential activation of caspase-9 and -3 proteolytic processing (31). Bcl-2 and Bcl-xL, which are the major anti-apoptotic proteins among the $\mathrm{Bcl}-2$ family members, block the function of proapoptotic proteins, including Bax (32). Although it has been reported that HDW induces cell apoptosis through the intrinsic apoptosis pathway (13-15), its effects on the Bcl-2 family in WEHI-3 cells remain unclear. HDW treatment significantly reduced the RNA expression of Bcl-2, and upregulated the expression levels of Bax in human colorectal cancer cells (33). A decreased $\mathrm{Bcl}-2 / \mathrm{Bax}$ ratio and Akt suppression were detected in HDW-treated human glioblastoma cells (27). The results of the present study have demonstrated that HDW had little effect on the expression of Bcl-2, Bcl-xL and Bak in WEHI-3 cells. Furthermore, recent studies have revealed that ATO induces cell apoptosis by regulating $\mathrm{Bcl}-2, \mathrm{Bcl}-\mathrm{xL}$ and $\mathrm{Bax}$ in multiple solid tumors $(31,32,34)$. In accordance with this, the present study has demonstrated that ATO inhibited the expression of $\mathrm{Bcl}-2$ and $\mathrm{Bcl}-\mathrm{xL}$, and increased the expression of Bak in WEHI-3 cells. In the present study, the results demonstrated that HDW synergizes with ATO to promote cell apoptosis by regulating different apoptotic molecules and inhibiting anti-apoptotic protein expression in WEHI-3 cells.

To the best of our knowledge, the present study demonstrated, for the first time, that HDW potentiated ATO-induced apoptosis in WEHI-3 cells. The results further revealed that HDW and ATO coordinately initiated the mitochondrial and DR apoptotic signaling pathways in order to trigger cell apoptosis in WEHI-3 cells. These observations provide novel evidence that the combination of HDW with ATO may be a promising strategy to increase the clinical efficacy of ATO in the treatment of APL.

\section{Acknowledgements}

The present study was supported by the Ministry of Science and Technology (grant no. MOST 104-2320-B-039-039) in Taipei, Taiwan.

\section{References}

1. Mathews V, Chendamarai E, George B, Viswabandya A and Srivastava A: Treatment of acute promyelocytic leukemia with single-agent arsenic trioxide. Mediterr J Hematol Infect Dis 3: e2011056, 2011.

2. Maeda H, Hori S, Nishitoh H, Ichijo H, Ogawa O, Kakehi Y and Kakizuka A: Tumor growth inhibition by arsenic trioxide (As2O3) in the orthotopic metastasis model of androgen-independent prostate cancer. Cancer Res 61: 5432-5440, 2001.

3. Shen ZY, Shen J, Cai WJ, Hong C and Zheng MH: The alteration of mitochondria is an early event of arsenic trioxide induced apoptosis in esophageal carcinoma cells. Int J Mol Med 5: 155-158, 2000.

4. Uslu R, Sanli UA, Sezgin C, Karabulut B, Terzioglu E, Omay SB and Goker E: Arsenic trioxide-mediated cytotoxicity and apoptosis in prostate and ovarian carcinoma cell lines. Clin Cancer Res 6: 4957-4964, 2000.

5. Lengfelder E, Hofmann WK and Nowak D: Impact of arsenic trioxide in the treatment of acute promyelocytic leukemia. Leukemia 26: 433-442, 2012.

6. Drolet B, Simard C and Roden DM: Unusual effects of a QT-prolonging drug, arsenic trioxide, on cardiac potassium currents. Circulation 109: 26-29, 2004.

7. Ducas RA, Seftel MD, Ducas J and Seifer C: Monomorphic ventricular tachycardia caused by arsenic trioxide therapy for acute promyelocytic leukaemia. J R Coll Physicians Edinb 41: 117-118, 2011.

8. Mumford JL, Wu K, Xia Y, Kwok R, Yang Z, Foster J and Sanders WE: Chronic arsenic exposure and cardiac repolarization abnormalities with QT interval prolongation in a population-based study. Environ Health Perspect 115: 690-694, 2007.

9. Vizzardi E, Zanini G, Antonioli E, D'Aloia A, Raddino R and Cas LD: QT prolongation: A case of arsenical pericardial and pleural effusion. Cardiovasc Toxicol 8: 41-44, 2008.

10. Pereira GC, Silva AM, Diogo CV, Carvalho FS, Monteiro P and Oliveira PJ: Drug-induced cardiac mitochondrial toxicity and protection: From doxorubicin to carvedilol. Curr Pharm Des 17: 2113-2129, 2011.

11. Lin CC, Kuo CL, Lee MH, Hsu SC, Huang AC, Tang NY, Lin JP, Yang JS, Lu CC, Chiang JH, et al: Extract of Hedyotis diffusa Willd influences murine leukemia WEHI-3 cells in vivo as well as promoting $\mathrm{T}$ - and $\mathrm{B}$-cell proliferation in leukemic mice. In Vivo 25: 633-640, 2011.

12. Li Q, Wang X, Shen A, Zhang Y, Chen Y, Sferra TJ, Lin J and Peng J: Hedyotis diffusa Willd overcomes 5-fluorouracil resistance in human colorectal cancer HCT-8/5-FU cells by downregulating the expression of $\mathrm{P}$-glycoprotein and ATP-binding casette subfamily $G$ member 2 . Exp Ther Med 10: 1845-1850, 2015.

13. Lin J, Chen Y, Wei L, Chen X, Xu W, Hong Z, Sferra TJ and Peng J: Hedyotis Diffusa Willd extract induces apoptosis via activation of the mitochondrion-dependent pathway in human colon carcinoma cells. Int J Oncol 37: 1331-1338, 2010.

14. Lin J, Wei L, Xu W, Hong Z, Liu X and Peng J: Effect of Hedyotis Diffusa Willd extract on tumor angiogenesis. Mol Med Rep 4: 1283-1288, 2011.

15. Liu Z, Liu M, Liu M and Li J: Methylanthraquinone from Hedyotis diffusa WILLD induces $\mathrm{Ca}(2+)$-mediated apoptosis in human breast cancer cells. Toxicol In Vitro 24: 142-147, 2010.

16. Lin M, Lin J, Wei L, Xu W, Hong Z, Cai Q, Peng J and Zhu D: Hedyotis diffusa Willd extract inhibits HT-29 cell proliferation via cell cycle arrest. Exp Ther Med 4: 307-310, 2012. 
17. Khandekar JD and Beck HH III: Delayed recurrences in primary fallopian tube carcinoma. South Med J 86: 1314-1315, 1993.

18. Zhang L, Zhang J, Qi B, Jiang G, Liu J, Zhang P, Ma Y and $\mathrm{Li} \mathrm{W}$ : The anti-tumor effect and bioactive phytochemicals of Hedyotis diffusa willd on ovarian cancer cells. J Ethnopharmacol 192: 132-139, 2016.

19. Sun G, Wei L, Feng J, Lin J and Peng J: Inhibitory effects of Hedyotis diffusa Willd. On colorectal cancer stem cells. Oncol Lett 11: 3875-3881, 2016.

20. Li YL, Zhang J, Min D, Hongyan Z, Lin N and Li QS: Anticancer Effects of 1,3-Dihydroxy-2-methylanthraquinone and the ethyl acetate fraction of hedyotis diffusa willd against HepG2 carcinoma cells mediated via apoptosis. PLoS One 11: e0151502, 2016.

21. Liu SP, Hsu CY, Fu RH, Huang YC, Chen SY, Lin SZ and Shyu WC: Sambucus williamsii induced embryonic stem cells differentiated into neurons. Biomedicine 5: 3, 2015.

22. Lu CC, Yang JS, Chiang JH, Hour MJ, Lin KL, Lin JJ, Huang WW, Tsuzuki M, Lee TH and Chung JG: Novel quinazolinone MJ-29 triggers endoplasmic reticulum stress and intrinsic apoptosis in murine leukemia WEHI-3 cells and inhibits leukemic mice. PLoS One 7: e36831, 2012.

23. Way TD, Tsai SJ, Wang CM, Ho CT and Chou CH: Chemical constituents of Rhododendron formosanum show pronounced growth inhibitory effect on non-small-cell lung carcinoma cells. J Agric Food Chem 62: 875-884, 2014.

24. Lin YJ, Ho TJ, Lin TH, Hsu WY, Huang SM, Liao CC, Lai CH, Liu X, Tsang H, Lai CC and Tsai FJ: P-coumaric acid regulates exon 12 splicing of the ATP7B gene by modulating hnRNP A1 protein expressions. Biomedicine (Taipei) 5: 10, 2015.

25. Lin TY, Fan CW, Maa MC and Leu TH: Lipopolysaccharidepromoted proliferation of Caco-2 cells is mediated by c-Src induction and ERK activation. Biomedicine (Taipei) 5: 10, 2015.

26. Kuo YJ, Yang JS, Lu CC, Chiang SY, Lin JG and Chung JG: Ethanol extract of Hedyotis diffusa willd upregulates G0/G1 phase arrest and induces apoptosis in human leukemia cells by modulating caspase cascade signaling and altering associated genes expression was assayed by cDNA microarray. Environ Toxicol 30: 1162-1177, 2015.
27. Zhang Y, Xie RF, Xiao QG, Li R, Shen XL and Zhu XG: Hedyotis diffusa Willd extract inhibits the growth of human glioblastoma cells by inducing mitochondrial apoptosis via AKT/ERK pathways. J Ethnopharmacol 158 Pt A: 404-411, 2014.

28. Zhang P, Zhang B, Gu J, Hao L, Hu F and Han C: The study of the effect of hedyotis diffusa on the proliferation and the apoptosis of the cervical tumor in nude mouse model. Cell Biochem Biophys 72: 783-789, 2015.

29. Gao JK, Wang LX, Long B, Ye XT, Su JN, Yin XY, Zhou XX and Wang ZW: Arsenic trioxide inhibits cell growth and invasion via down- regulation of Skp2 in pancreatic cancer cells. Asian Pac J Cancer Prev 16: 3805-3810, 2015.

30. Jiang L, Wang L, Chen L, Cai GH, Ren QY, Chen JZ, Shi HJ and Xie YH: As2O3 induces apoptosis in human hepatocellular carcinoma HepG2 cells through a ROS-mediated mitochondrial pathway and activation of caspases. Int J Clin Exp Med 8: 2190-2196, 2015.

31. Jiang H, Ma Y, Chen X, Pan S, Sun B, Krissansen GW and Sun X: Genistein synergizes with arsenic trioxide to suppress human hepatocellular carcinoma. Cancer Sci 101: 975-983, 2010.

32. Chen G, Wang K, Yang BY, Tang B, Chen JX and Hua ZC: Synergistic antitumor activity of oridonin and arsenic trioxide on hepatocellular carcinoma cells. Int J Oncol 40: 139-147, 2012.

33. Lin J, Li Q, Chen H, Lin H, Lai Z and Peng J: Hedyotis diffusa Willd. extract suppresses proliferation and induces apoptosis via IL-6-inducible STAT3 pathway inactivation in human colorectal cancer cells. Oncol Lett 9: 1962-1970, 2015.

34. Rangwala F, Williams KP, Smith GR, Thomas Z, Allensworth JL, Lyerly HK, Diehl AM, Morse MA and Devi GR: Differential effects of arsenic trioxide on chemosensitization in human hepatic tumor and stellate cell lines. BMC Cancer 12: 402, 2012. 